\title{
SYMPTOMS OF ANXIETY AND TENSION AND THE ACCOMPANYING PHYSIOLOGICAL CHANGES IN THE MUSCULAR SYSTEM \\ BY
}

\author{
PETER SAINSBURY and J. G. GIBSON
}

From the Institute of Psychiatry (University of London), the Maudsley Hospital, London

It has already been shown that anxiety is often accompanied by muscle over-activity (Jacobson, 1938). Malmo and Shagass (1949a) found that the amplitude of action potentials recorded from the neck muscles of patients with anxiety states was significantly higher than in healthy controls when both were stressed by applying painful stimuli to the forehead; but the action-potential ratings also correlated with movements drawing the head away from the stimulus. Malmo and Shagass (1949b) used the same technique when they found that anxious patients with head complaints had significantly more activity in the neck muscles during stress than those without. Wolff (1948) also recorded over-activity in the electromyograms of the neck and scalp muscles of anxious patients. When the anxiety was diminished the over-activity and the headache disappeared. Finally, Holmes and Wolff (1952) found that patients with backache had pain and a generalized over-activity of the trunk muscles in situations which engendered conflict and insecurity, or feelings of hostility, frustration, and guilt. As the findings in the last two papers were presented in the form of typical case histories it was not possible to estimate how regularly headache or backache and muscular over-activity were associated.

We aimed, by means of controlled experiments, to study the relations between the symptoms complained of by anxious patients and the activity in the skeletal muscles. In order to limit the experimental conditions to the simplest we measured the muscle activity occurring in our subjects when they were relaxing, remaining still, and, where possible, in a position which avoided reflex postural tone in the muscles being investigated. The activity recorded under these conditions we called muscle tension.

Our hypotheses were first, that an increase in innervation of the skeletal muscles accompanies anxiety so that in anxious patients attempting to relax not only will muscle tension be greater than in healthy subjects, but those patients with most clinical evidence of anxiety and "tension" will have the most muscle tension. It follows that the increase in muscle activity expected in the anxious would be evident in a number of well separated groups of voluntary muscles.

Secondly, that the physiological mechanism underlying some of the common symptoms of anxiety is increased muscle tension, so that more muscle tension would be recorded in muscles in which such symptoms were felt than in those where they were not.

\section{Subjects}

Thirty-two consecutive patients were investigated. The records of two had to be discarded as they were spoiled by electrical artefacts. Of the remaining 30 , 10 were male and 20 female, and their mean age was 39.5 years, ranging from 27 to 58 years. Fifteen were diagnosed as cases of anxiety states ; one of these was also an alcoholic. Thirteen were of depression with anxiety and "tension", one of whom was also suffering from anorexia nervosa, and there were two patients with obsessional neuroses and marked anxiety.

\section{Method}

The patients' symptoms of anxiety and tension were scored by means of an inventory based on Cameron's analysis (1944) of the patterns of anxiety and on the results of a survey by one of us (J.G.G.) in which 29 senior psychiatrists were presented with a questionnaire designed to elicit and to afford a basis for discussion of the clinical observations by which they ascribed "tension" to a patient. Those items which the majority were agreed upon were included in the present inventory.

The inventory was completed in the course of an interview given during the recording in which the patients were encouraged to describe their symptoms freely. Each positive item entered was accompanied by the patient's verbatim account.

The inventory was divided into three parts. The first assessed the patient's affective state, his reports 

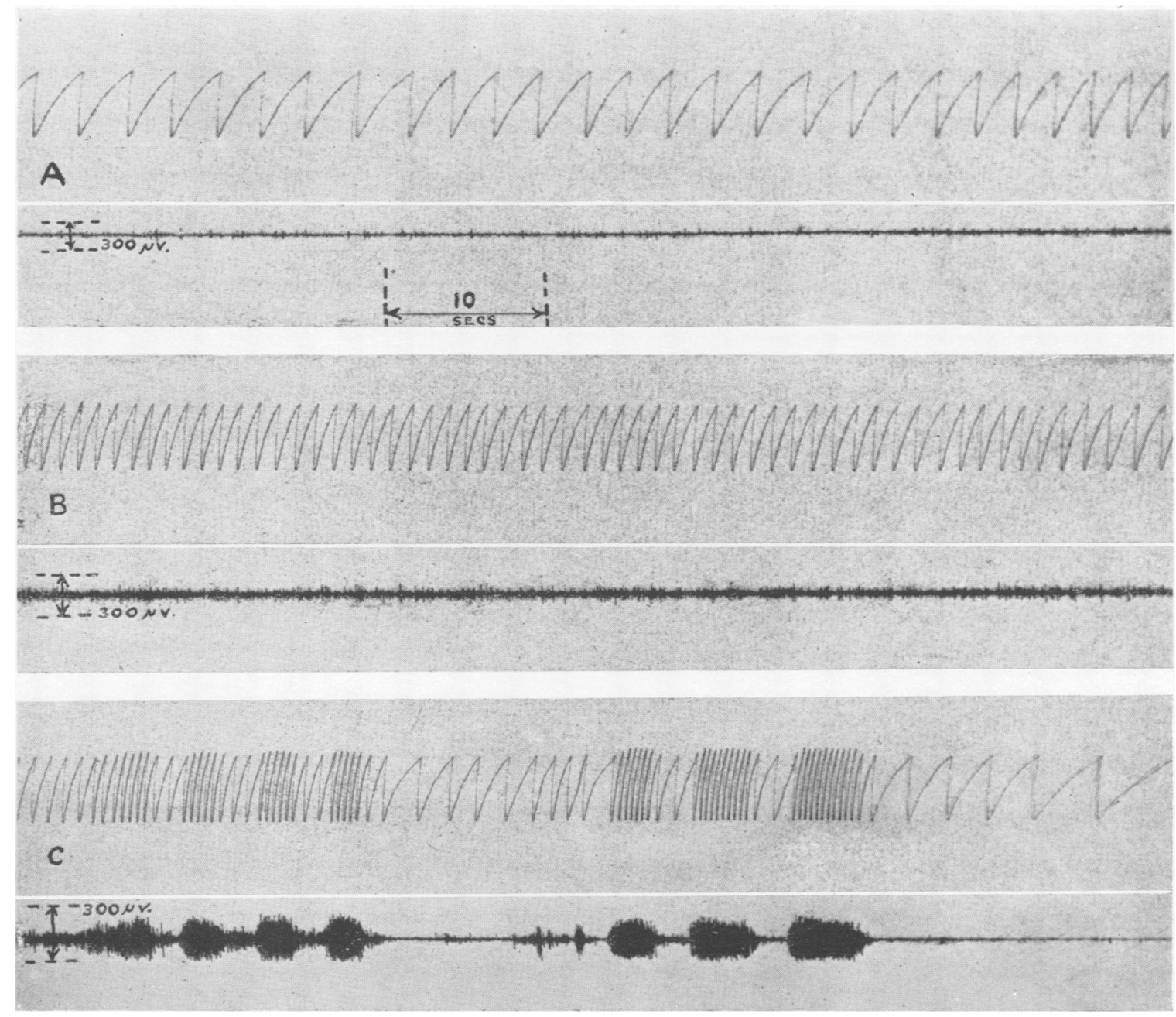

Fig. 1.-Three records (one minute approximately) to show counts (upper tracing), and action potentials (lower tracing). A-Relaxing : moderate muscle tension.

B-Increase in muscle tension following interview.

C-To show effect of movement of arms : compare this erratic record with the regular tension in $\mathbf{A}$ and $\mathbf{B}$.

of his feelings of anxiety and tension: he was asked if he felt tense and unable to relax, anxious and apprehensive, irritable and touchy, restless and fidgety, and whether on edge and keyed up at the present moment. The first three of these items were scored nil, 1 or 2 , the remaining two as either absent or present (nil or 1). The latter method of scoring was adopted when marking the second part of the inventory which recorded the presence now, or frequently during the past 10 days, of bodily symptoms believed to be muscular in origin : headache or head sensations now ; aching, feelings of stiffness, or drawing sensations in neck, arms, back, or elsewhere ; tremulousness, starting, or waking up with a sudden jerk. The items placed in the last part of the inventory were symptoms which have also been claimed to be manifestations of muscle over-activity, but with less certainty. They were undue fatigue, a sense of moving awkwardly or stiffly, sensations of numbness and fluttering, and visual disturbances.

In the subsequent calculations we used $(a)$ the total score obtained from the whole inventory, (b) that part giving a score of the patient's feelings of tension and anxiety, or $(c)$ the muscular symptoms score, depending on which of these we required to relate to muscle tension (Table I).

Muscle activity was measured by means of a two 
TABLE I

THE INCIDENCE OF SYMPTOMS ENUMERATED IN THE INVENTORY GIVEN TO 30 PATIENTS WITH ANXIETY AND TENSION STATES

\begin{tabular}{|c|c|c|c|}
\hline Symptoms & Complaints & $\begin{array}{l}\text { Inci- } \\
\text { dence } \\
\text { (No.) }\end{array}$ & $\begin{array}{l}\text { Inci- } \\
\text { dence } \\
(\%)\end{array}$ \\
\hline $\begin{array}{l}\text { From which the scores of } \\
\text { the patient's feeling of } \\
\text { anxiety and tension were } \\
\text { obtained }\end{array}$ & $\begin{array}{l}\text { 1. Tense, unable to } \\
\text { relax, on edge, etc. } \\
\text { 2. Anxious, apprehen- } \\
\text { sive } \\
\text { 3. Irritable, touchy } \\
\text { 4. Restless, fidgety } \\
\text { 5. Tense during re- } \\
\text { cording }\end{array}$ & $\begin{array}{l}30 \\
29 \\
22 \\
24 \\
22\end{array}$ & $\begin{array}{r}100 \\
96 \\
73 \\
79 \\
73\end{array}$ \\
\hline $\begin{array}{l}\text { From which the scores of } \\
\text { bodily symptoms attri- } \\
\text { butable to sustained } \\
\text { muscular over-activity } \\
\text { were obtained }\end{array}$ & $\begin{array}{l}\text { 1. Headache while re- } \\
\text { cording } \\
\text { 2. Arms ache or stiff } \\
\text { 3. Neck aches or stiff } \\
\text { 4. Back aches or stiff } \\
\text { 5. Aches or stiffness } \\
\text { in other bodily areas } \\
\text { 6. Tremulousness } \\
\text { 7. Starts unduly, wakes } \\
\text { with a jerk }\end{array}$ & $\begin{array}{r}7 \\
13 \\
19 \\
16 \\
\\
20 \\
15 \\
19\end{array}$ & $\begin{array}{l}22 \\
43 \\
63 \\
53 \\
\\
66 \\
50 \\
63\end{array}$ \\
\hline $\begin{array}{l}\text { Additional symptoms which } \\
\text { contributed to the scores } \\
\text { for the total clinical } \\
\text { manifestations of anxiety } \\
\text { and tension }\end{array}$ & $\begin{array}{l}\text { 1. Undue fatigue } \\
\text { 2. A sense of stiff, } \\
\text { clumsy or unfree } \\
\text { movement } \\
\text { 3. Sensations of numb- } \\
\text { ness, fluttering, etc. } \\
\text { 4. Visual disturbances }\end{array}$ & $\begin{array}{l}21 \\
10 \\
12\end{array}$ & $\begin{array}{l}76 \\
\\
69 \\
\\
33 \\
40\end{array}$ \\
\hline
\end{tabular}

channel electromyograph (E.M.G.) with a specially designed integrating circuit.* In each channel the muscle potentials were fed from a preamplifier first to an oscilloscope visible to the operator; this enabled him to monitor the record, ensure its freedom from artefact, and to observe whether the record was of the pattern to be expected from a tense muscle, namely, an evenly sustained interference pattern of muscle potentials, free from the sudden high-voltage bursts of activity produced by movements; secondly to a pen recorder which made a permanent tracing. Finally, the action potentials were summed in an electronic integrating circuit which operated two electromagnetic counters.

Calibration tests showed that the rate of counting bore a linear relation both to the frequency of the input when the voltage was constant and to the input voltage when the frequency was constant. The counts obtained from a muscle, therefore, would be proportional to the number of motor units contracting, which determines the amplitude (voltage) of the signals picked up, and to the frequency at which they are contracting. Fig. 1 illustrates three typical tracings, about one minute in duration, of the action potentials and counts obtained from the left forearm of an anxious patient. In tracing $\mathbf{A}$ he is attempting to relax but

* We are indebted to the designer, Mr. Peter Styles of St. Thomas's Hospial, who constructed the electromyograph, and to Professor Hospital, who constructed the electromyograph, and to Professor logist in Charge of the Nuffield Research Unit at this Institute, who drew up the specifications for it.
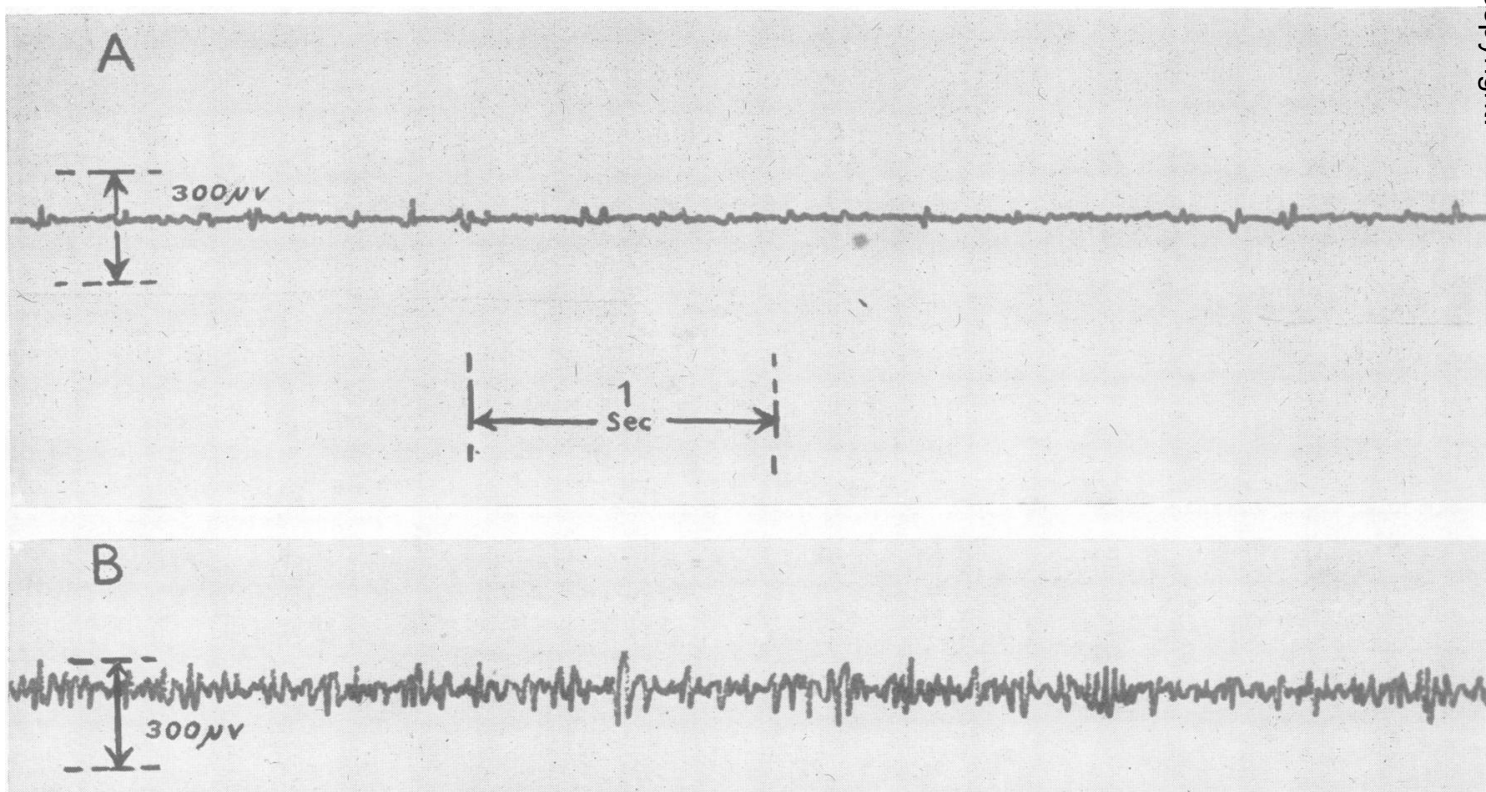

FIG. 2.-Pen recording of action potentials at $6 \mathrm{~cm} . / \mathrm{sec}$. to show detail of part of A and B in Fig 1 . 
shows moderate muscle tension ( 24 counts a minute); in $\mathrm{B}$ he is still relaxing but activity has increased following a disturbing interview (55 counts a minute). In both $\mathrm{A}$ and $\mathrm{B}$ the action potentials are regularly sustained (muscle tension) ; for comparison, $\mathrm{C}$ shows the erratic tracing which accompanied gestural movements of the arm during interview. Fig. 2 shows details taken from $A$ and $B$ which were recorded simulianeously by a pen recorder at $6 \mathrm{~cm}$. a second.

The method of scoring adopted was to record the counts from both channels at minute intervals, and in the subsequent calculations to take the mean of the minute scores.

\section{Procedure}

The patients lay on a standard hospital bed, their skins were cleaned with spirit, briskly rubbed with electrode jelly and surface electrodes applied. The latter were silver cups $1 \mathrm{~cm}$. in diameter, filled with electrode jelly, and strapped on with adresive plaster. Those from channel 1 were placed over the crests of the left forearm extensors, and those from channel 2 over the frontalis above the centre of each eyebrow. A saline pad on the right leg was used as an earth. The patient was reassured, then told to remain as still as he comfortably could, to relax as far as possible, and to close his eyes. Previous trials had indicated that seven minutes was the most suitable period of relaxation. He was then interviewed for about 20 minutes; during this time the inventory was completed. Then a second relaxing period of seven minutes was recorded in a similar manner to the first.

The first 15 patients were seen on a second occasion when recordings were obtained from the posterior cervical muscles and the extensors of the left foot. For these recordings the electrodes were small rubber sponges soaked in saline and containing a loop of silver wire. The patient sat in a chair and was instructed to relax and look at a piece of grey paper 4 inches square placed at arm's length and at eye level. Satisfactory, movement-free recordings were obtained while relaxing for seven minutes.

The reliability of the method was estimated by the test-retest procedure. The product-moment correlation between the scores for the initial and final seven minutes of relaxation in the 30 patients of this study was $0.90 \pm 0.023$ for the arms, and $0.94 \pm 0.062$ for the forehead. We concluded from these findings that reliable scores are obtained by this method, and that the patients were characterized by a high degree of constancy of muscle tension from one moment to another.

\section{Results}

Muscle Tension in Healthy and Anxious Subjects.A preliminary investigation was made to test the hypothesis that an increased innervation of the voluntary muscles is a physiological accompaniment of anxiety by comparing muscle tension in anxious and healthy subjects. It was expected that this experiment would also give an indication of the sensitivity of the electromyographic method in discriminating between levels of muscle tension.

The muscle tension recorded from $\mathrm{m}$. frontalis of 26 patients diagnosed as anxiety states, and of 30 healthy soldiers was measured while they relaxed with their eyes closed as described above. The mean muscle tension score of the former was 9.59 counts min. (S.D. 5.14) and of the latter 5.23 counts $\mathrm{min}$. (S.D. 3.01). On testing for a significant difference $t$ was found to be $3 \cdot 86$, which is highly significant $(\mathrm{P}>0.001)$. The anxious patients, therefore, showed more muscle tension than the healthy subjects and the method discriminated well between the two groups.

Character and Frequency of Symptoms of Tense, Anxious Patients. - The frequency of the complaints enumerated in the inventory is summarized in Table I. It follows from the method of selecting the patients that complaints of feeling tense and anxious would be very common in them. In fact, all the patients complained of feeling tense, and 22 experienced it even while they "relaxed" on the bed at the time of the recording ; 29 were feeling anxious. The complaints of feeling restless and irritable were also very common.

When each patient was asked to describe further his feeling of tension, 24 depicted it as a bodily sensation in one or more of the following terms : "A feeling of tightness, as if muscles taut", "whole body tightens up and pains when I am worked up ", " tight as if drawn up ", " a drawing up or dragging feeling ", " a stiffness of the muscles", " stiff all over", "as if made of iron-all muscles immovable", " a soreness or bruised feeling", " cramped", " unable to relax my body". Twelve of these described tension as something experienced exclusively in their muscles while six others experienced it solely as a state of feeling. They used such phrases as " on edge", " keyed up ", " over-alert all the time", " tensed up as if I wanted to scream", " jittery and unable to settle".

Many of the patients asserted that their primary complaint of "tension" was attributable to the unrelaxed or contracted state of their muscles $(79 \%)$, that they felt relief from this state with barbiturates or when relaxing in a hot bath $(59 \%)$, 
and that they had observed a close relationship between the intensity of this feeling of tension and emotionally disturbing experiences $(50 \%)$.

Relations between Symptom Scores and Measures of Muscle Tension.-A comparison was made between the muscle activity in patients with most clinical evidence of tension and anxiety, and in patients with the least.

The patients were divided, therefore, into two groups by taking the scores they obtained on the whole inventory of their symptoms and finding the median. The means of the muscle tension scores (measured by the E.M.G.) were calculated for those above and below the median. A t-test showed differences between the mean scores of muscle tension in the two groups at the following levels of significance; 0.025 for the frontalis, 0.05 for the forearm extensors, and 0.01 for the combined frontalis and arm scores (Table II).

The median of the scores of the patients' reports of their feelings of tension and anxiety (part 1 of inventory) was found, and again the means of the E.M.G. muscle tension scores of those patients above and those below the median were tested for significant differences. The mean muscle tension in the forearm extensors, in the frontalis, and in the two combined were greater in the patients who felt more tense. The levels of significance were $0.05,0.01$, and 0.0025 respectively (Table II). Having found this association an attempt was made to assess its intensity by correlating the patients' scores of their feelings and their total muscle tension scores. The product-moment correlation $(r=0.45)$ was significant.

Finally, the combined muscle tension and the arm muscle tension of patients with more than the median scores for bodily symptoms attributed to muscular over-activity (part 2 of the inventory) were significantly greater than those with less. The muscle tension in the forehead did not differentiate the two groups, but the product-moment correlation between scores for bodily symptoms and for muscle tension was significant $(\mathrm{r}=0.49)$.

It may be concluded, therefore, that those patients with more than the median number of clinical manifestations of tension and anxiety showed significantly more muscle action potentials of a pattern to be expected where the muscles are in a condition of sustained contraction than did patients with less than the median score. It was therefore possible to differentiate between the more and the less muscularly tense patients by scoring the items describing their feelings of tension listed in the inventory; but the items in the inventory dealing with the bodily symptoms of muscle overactivity served to discriminate only between those with and those who had no such muscle tension in the forearm muscles.

The Relation between Certain Bodily Sensations and Muscle Tension.-Certain bodily sensations were studied.

Headache and Head Sensations.-At the time of recording seven of the 30 patients complained of headache or head sensations which they described as follows : "tight band across head-a pressure band ", "pressure and tightness across forehead which becomes painful if I am tensed up", "a soreness and bruised feeling at the top and back of the head that comes on with keyed-up feelings", " a dull ache or dragging pain spreading from back

TABLE II

DIFFERENCES IN E.M.G. MUSCLE TENSION SCORES OF ANXIOUS PATIENTS WITH CLINICAL SCORES OF TENSION ABOVE AND BELOW THE MEDIAN

\begin{tabular}{|c|c|c|c|c|c|c|c|c|c|c|}
\hline \multirow{4}{*}{$\begin{array}{l}\text { Muscle } \\
\text { Tension }\end{array}$} & & \multicolumn{9}{|c|}{ Clinical Manifestations of Tension and Anxiety Recorded on the Inventory } \\
\hline & & \multicolumn{3}{|c|}{$\begin{array}{l}\text { Total Symptom } \\
\text { Scores }\end{array}$} & \multicolumn{3}{|c|}{$\begin{array}{l}\text { Feelings of Anxiety and } \\
\text { Tension Scores }\end{array}$} & \multicolumn{3}{|c|}{$\begin{array}{l}\text { Muscular Symptom } \\
\text { Scores }\end{array}$} \\
\hline & & $\begin{array}{l}\text { Above } \\
\text { Median }\end{array}$ & & $\begin{array}{l}\text { Below } \\
\text { Median }\end{array}$ & $\begin{array}{l}\text { Above } \\
\text { Median }\end{array}$ & & $\begin{array}{l}\text { Below } \\
\text { Median }\end{array}$ & $\begin{array}{l}\text { Above } \\
\text { Median }\end{array}$ & & $\begin{array}{l}\text { Below } \\
\text { Median }\end{array}$ \\
\hline & No. & 14 & & 12 & 9 & & 14 & 14 & & 11 \\
\hline $\begin{array}{c}\text { Total } \\
\text { Forehead } \\
\text { and arm }\end{array}$ & $\begin{array}{c}\text { Mean E.M.G.Scores } \\
\sigma \mathrm{W} \\
\mathrm{t} \\
\mathrm{P}\end{array}$ & $31 \cdot 12$ & $\begin{array}{l}6.99 \\
2 \cdot 51 \\
0.01\end{array}$ & $13 \cdot 58$ & $33 \cdot 77$ & $\begin{array}{l}6 \cdot 03 \\
3 \cdot 26 \\
0 \cdot 0025\end{array}$ & $14 \cdot 13$ & 31.48 & $\begin{array}{l}4 \cdot 66 \\
2 \cdot 94 \\
0 \cdot 005\end{array}$ & $17 \cdot 78$ \\
\hline Frontalis & $\begin{array}{c}\text { Mean E.M.G.Scores } \\
\sigma \mathrm{W} \\
\mathrm{t} \\
\mathbf{P}\end{array}$ & $21 \cdot 83$ & $\begin{array}{l}5 \cdot 53 \\
2 \cdot 19 \\
0.025\end{array}$ & $\overline{9} \cdot \overline{68}$ & $23 \cdot 58$ & $\begin{array}{l}5 \cdot 10 \\
2 \cdot 71 \\
0 \cdot 01\end{array}$ & $9 \cdot 74$ & $21 \cdot 24$ & $\begin{array}{l}6 \cdot 35 \\
1 \cdot 15 \\
\text { N.S. }\end{array}$ & 13.92 \\
\hline $\begin{array}{l}\text { L. forearm } \\
\text { extensors }\end{array}$ & $\begin{array}{c}\text { Mean E.M.G.Szores } \\
\sigma \mathrm{w} \\
\mathrm{t} \\
\mathbf{P}\end{array}$ & $9 \cdot 32$ & $\begin{array}{l}2 \cdot 72 \\
1.99 \\
0.05\end{array}$ & 3.90 & $10 \cdot 19$ & $\begin{array}{l}3.07 \\
1.89 \\
0.05\end{array}$ & $4 \cdot 39$ & $10 \cdot 24$ & $\begin{array}{l}2 \cdot 88 \\
2 \cdot 12 \\
0 \cdot 025\end{array}$ & 3.86 \\
\hline
\end{tabular}

$\mathbf{P}=$ The probability corresponding to the single-tailed or asymmetrical t-test (Fisher's tables). 
of neck to eyes ", " a sort of tightness-dull ache". Six said that their head complaints increased when they were disturbed and tense, and five had noticed that sedatives or relaxing in a hot bath relieved them; another patient observed that crying relieved her symptoms.

The muscle tension in the frontalis was measured while the patients relaxed on a bed with their eyes shut. When the mean of the E.M.G. frontalis scores of the seven patients with headaches was compared with the mean of the scores of those without headaches, the difference was found to be highly significant. The probability that the higher activity in the headache group could be attributed to chance was less than $1: 400$ (Table III).

One patient developed a headache during the recording. The counts per minute during seven minutes relaxing without headache were 30 ; this increased to 85 when the headache was present in the final seven-minute relaxing. Two other patients began the recording with headaches which disappeared during the interview. In both cases the muscle tension score in the second relaxing period was very significantly lower, having dropped by 6 and 8.5 counts per minute. The graph in Fig. 3 illustrates the first of these cases.

A difference in muscle tension between those with and without headache was found only in the frontalis muscle; the forearm muscle tension of the two groups was not significantly different. In these cases, therefore, the increase in muscle tension tended to be localized to, or to predominate in the muscles supposedly giving rise to the symptom. This interpretation is corroborated by the analogous findings in those patients who complained of arm symptoms.

Arm Symptoms.-Fourteen patients complained of stiffness, "rheumatics" (without joint pains), and aching in the arms. Some of these commented that their arms were tensed or tightened up, cramped, or subject to drawing feelings. In only three patients were these symptoms present while they relaxed on the bed during the recording. The muscle tension in the extensor muscles of the left forearms of these 14 patients was significantly higher $(P=$ 0.0025 ) than that recorded from the 16 patients without symptoms referrable to the arms. There was no significant difference in the frontalis tension in these two groups of patients, that is to say, tension was again localized to the bodily area of the symptom.

Tremulousness.-This symptom is considered here because the tremulousness was often referred to the arms in addition to being experienced as a generalized shakiness. It was of interest to find, therefore, that the 15 patients with this complaint had a significantly greater muscle tension in the arm extensors and in the frontalis than had the remaining 15 who were not tremulous (Table III). As far as it is justified to argue from an investigation limited to two bodily areas, the increase in muscle tension in tremor due to emotion is widespread.

Neck Symptoms.-Recordings were obtained from the posterior cervical muscles of 15 patients, four of whom complained of pain or stiffness in the neck. These four showed a significantly greater level of muscle activity than did the 11 without neck

TABLE III

ASSOCIATION BETWEEN BODILY SYMPTOMS ATTRIBUTABLE TO MUSCLE TENSION AND DIRECT MEASURE OF MUSCLE TENSION IN VARIOUS AREAS

\begin{tabular}{|c|c|c|c|c|c|c|c|c|c|c|c|c|c|c|c|}
\hline \multirow{4}{*}{$\begin{array}{l}\text { Muscle } \\
\text { Tension }\end{array}$} & & \multicolumn{10}{|c|}{ Symptoms of Pain and Tightness in } & \multicolumn{4}{|c|}{ Other Symptoms } \\
\hline & & \multicolumn{2}{|c|}{ Head } & \multicolumn{2}{|c|}{ Arm } & \multicolumn{2}{|c|}{ Neck } & \multicolumn{2}{|c|}{ Back } & \multirow{2}{*}{$\frac{\text { Other }}{\text { With }}$} & \multirow{2}{*}{$\frac{\text { Areas }}{\begin{array}{c}\text { With- } \\
\text { out }\end{array}}$} & \multicolumn{2}{|c|}{ Tremor } & \multicolumn{2}{|c|}{ Startles } \\
\hline & & With & $\begin{array}{l}\text { With- } \\
\text { out }\end{array}$ & With & $\begin{array}{l}\text { With- } \\
\text { out }\end{array}$ & With & $\begin{array}{l}\text { With- } \\
\text { out }\end{array}$ & With & $\begin{array}{l}\text { With- } \\
\text { out }\end{array}$ & & & With & $\begin{array}{c}\text { With- } \\
\text { out }\end{array}$ & With & $\begin{array}{l}\text { With- } \\
\text { out }\end{array}$ \\
\hline & No. & 7 & 23 & 14 & 16 & 19 & 11 & 17 & 13 & 10 & 20 & 15 & 15 & 19 & 11 \\
\hline Frontalis & $\begin{array}{c}\text { Mean E.M.G. Scores } \\
\sigma \mathrm{w} \\
\mathrm{t} \\
\mathbf{P}\end{array}$ & $\begin{array}{r}31 \cdot 26 \\
5 \\
3 \\
0\end{array}$ & $\begin{array}{l}11 \cdot 79 \\
48 \\
55 \\
0025\end{array}$ & $\begin{array}{r}21 \cdot 08 \\
5 . \\
1 . \\
\mathrm{N}\end{array}$ & $\begin{array}{l}12 \cdot 18 \\
34 \\
67 \\
. S .\end{array}$ & $\begin{array}{r}16 \cdot 19 \\
4 \\
0 \\
N\end{array}$ & $\begin{array}{l}16 \cdot 57 \\
86 \\
07 \\
. S .\end{array}$ & $\begin{array}{r}16 \cdot 79 \\
5 \\
0 \\
N\end{array}$ & $\begin{array}{l}15 \cdot 74 \\
64 \\
19 \\
.5\end{array}$ & $\begin{array}{r}15 \cdot 02 \\
5 \\
0 \\
N\end{array}$ & $\begin{array}{l}14 \cdot 06 \\
28 \\
18 \\
. S\end{array}$ & $\begin{array}{r}21 \cdot 19 \\
5 \\
1 \\
0\end{array}$ & $\begin{array}{l}11 \cdot 48 \\
27 \\
82 \\
05\end{array}$ & $\begin{array}{r}20 \cdot 12 \\
5 \\
1 \\
0\end{array}$ & $\begin{array}{l}9 \cdot 79 \\
47 \\
89 \\
05\end{array}$ \\
\hline Arm & $\begin{array}{l}\text { Mean E.M.G. Scores } \\
\qquad \begin{array}{l}\sigma \mathbf{w} \\
\mathbf{t} \\
\mathbf{P}\end{array}\end{array}$ & $\begin{array}{r}9 \cdot 40 \\
3 . \\
1 \cdot \\
\mathrm{N}\end{array}$ & $\begin{array}{l}12^{6 \cdot 10} \\
06 \\
.5\end{array}$ & $\begin{array}{r}10 \cdot 78 \\
2 . \\
3 . \\
0\end{array}$ & $\begin{array}{l}32^{3 \cdot 46} \\
16 \\
0025\end{array}$ & $\begin{array}{r}8 \cdot 16 \\
2 . \\
1 . \\
\mathrm{N}\end{array}$ & $\begin{array}{l}72^{4 \cdot 65} \\
29 \\
. S .\end{array}$ & $\begin{array}{r}7 \cdot 32 \\
2 \\
0 \\
N\end{array}$ & $\begin{array}{l}71^{6 \cdot 29} \\
38 \\
.5\end{array}$ & $\begin{array}{r}4 \cdot 12 \\
2 \\
1 \\
\mathrm{~N}\end{array}$ & $\begin{array}{l}55^{3 \cdot 57} \\
61 \\
.5\end{array}$ & $\begin{array}{r}9 \cdot 56 \\
2 \\
2 \\
0\end{array}$ & $\begin{array}{l}4^{4 \cdot 19} \\
41^{23} \\
025\end{array}$ & $\begin{array}{r}8 \cdot 60 \\
2 \\
1 \\
0\end{array}$ & $\begin{array}{l}3 \cdot 90 \\
66 \\
77 \\
05\end{array}$ \\
\hline Neck & $\begin{array}{c}\text { Mean E.M.G. Scores } \\
\qquad \begin{array}{l}\sigma \mathrm{W} \\
\mathrm{t} \\
\mathbf{P}\end{array}\end{array}$ & E & E & E & E & $\begin{array}{r}38 \cdot 65 \\
7 . \\
3 . \\
0 .\end{array}$ & $\begin{array}{l}11 \cdot 97^{*} \\
51 \\
55 \\
0025\end{array}$ & E & E & $\overline{-}$ & - & E & E & E & E \\
\hline
\end{tabular}

$\mathbf{P}=$ The probability corresponding to the single-tailed or asymmetrical t-test (Fisher's tables)

* In this instance $\mathbf{N}=15$, four with neck complaints and 11 without 
symptoms. The muscle tension in the forearm muscles was not significantly different in the two groups with and without neck symptoms, nor was the muscle tension in the frontalis. So again the principal increase in muscle tension was in those muscles to which the symptom had been ascribed by the patient (Table III).

Backache.-Seventeen patients complained of aching, stiffness, or tightness in the back. Neither in the forearm muscles nor in the frontalis was the muscle tension in these cases greater than in those without backache. No recordings were made from the back. The negative findings are, nevertheless, consistent with the tendency observed above for muscle tension to predominate in the muscles in which the patient feels the symptom.

Aches and Stiffness in Other Bodily Areas.-Ten patients complained of aching in the shoulders,

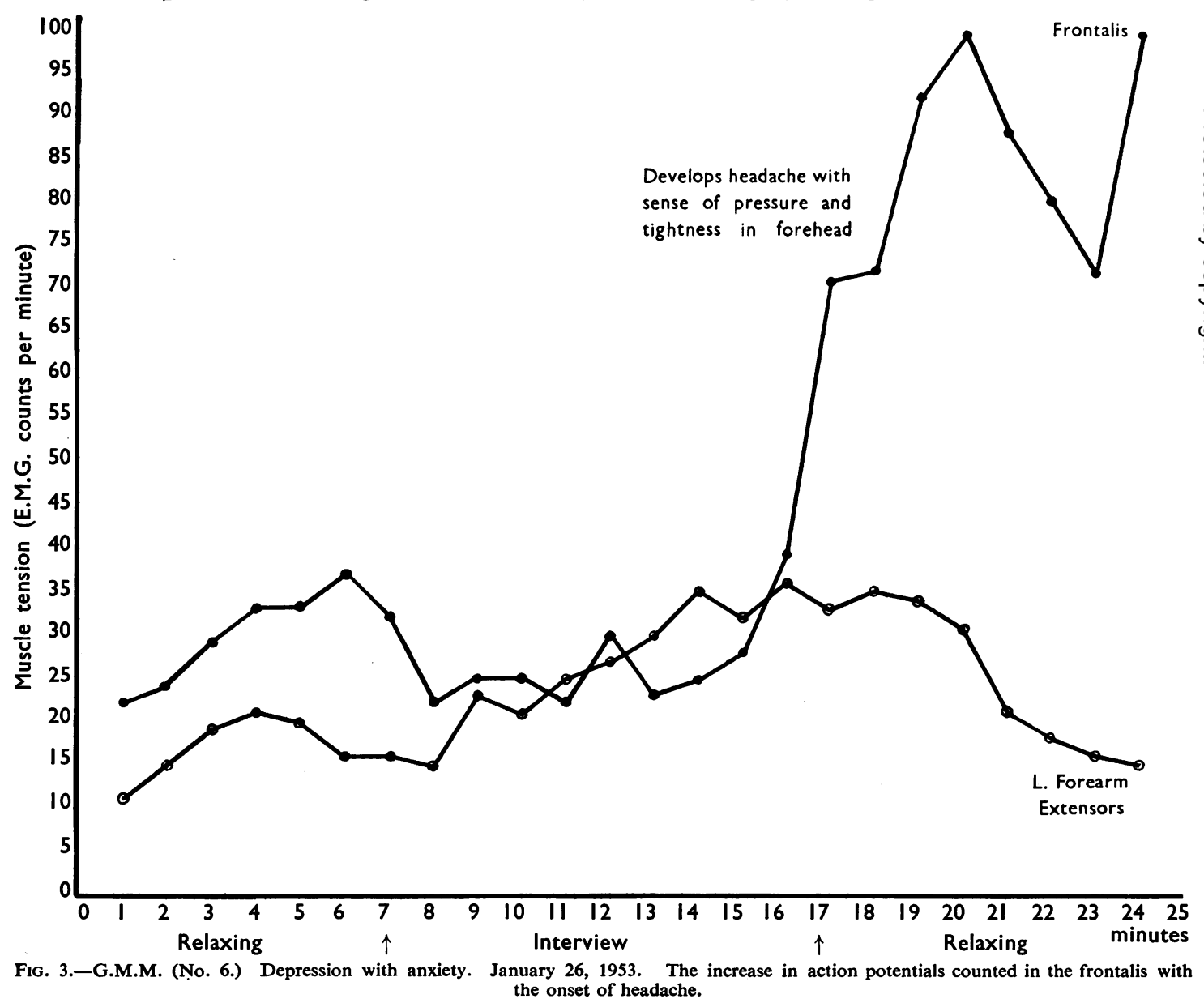

Fig. 3.-G.M.M. (No. 6.) Depression with anxiety. January 26,1953 . The increase in action potentials counted in the frontalis with the onset of headache.

jaw, legs, etc., which was associated with emotional disturbance. But they also could not be differentiated from the remaining 20 by recording the muscle tension in the forehead and forearm. In one patient, however, who complained of tenseness principally in the face and jaw, very high counts were obtained when electrodes were placed on the masseters.

Starts Unduly or Wakes with a Sudden Jerk.-A significant difference (at the 5\% level) was obtained between the means of the muscle tension scores obtained from the arms and the foreheads of the 19 patients who admitted to having this symptom and the mean scores of 11 who did not. This finding is consistent with the view that the tendency to start increases when the muscles are in a state of contraction.

Other Symptoms Included in the Total Inventory.Undue fatigue, feelings of clumsiness and unfree 
movements, sensations of numbness, etc., and visual disturbances could not be differentiated by our methods from those without these symptoms.

Tendency for Generalized Muscular Tension. -In 15 of the patients muscle tension scores were obtained concurrently from the frontalis, left forearm extensors, extensors of the left foot, and posterior cervical muscles. The scores from these four areas were each placed in rank order and the coefficient of concordance (W) was estimated. The value for $W$ obtained $(0.45)$ was significant at the $5 \%$ level. This finding suggests that an increase in bodily tension in one area is reliably associated with an increase in other areas.

\section{Discussion}

Malmo and Shagass (1949) had shown that in anxious patients the muscular activity in the neck increased proportionately with the intensity of the stress to which they were exposed (painful stimulation of the forehead) and the increase with stress was greater in the patients than in healthy controls. One of us had found that muscular activity in healthy subjects also increased when they were made anxious by everyday medical procedures such as recording their blood pressures. It has now been found that differences in muscle activity could be observed between anxious patients and healthy controls, even when the subjects were simply relaxing on a bed. Malmo and Shagass had been able to show a difference between their patients and controls only during stress; they concluded that it was the excessive physiological response to stress shown by anxious patients which distinguished them from the normal.

These studies suggest that muscle activity accompanies anxiety. The present investigation carries the quantitative analysis of the relation further. The more the patient experiences tension and anxiety subjectively the higher his muscle tension. This was evident in two well-separated areas, the frontalis and the forearm extensors, which makes it likely that all the voluntary muscles of the body tend to be over-active in these conditions. Three other results support this possibility: (1) the positive correlation $(r=0.45)$ between the scores of the patients' feelings of anxiety and the level of muscle activity recorded from the arm and forehead; (2) the significant concordance between the muscle activity in the forehead, neck, arm, and leg; (3) the observations that the patients with the two symptoms most likely to be dependent upon a general increase in muscle tension, starting and tremulousness, had muscle tension scores which were significantly higher than those of control patients without, in both the forearm extensors and the frontalis. It may be concluded that in patients who feel tense and anxious there is a widespread increase in muscle tension. However, we also observed a tendency for the increase in muscle activity to be more evident in some muscle groups than in others : patients with symptoms which they referred to the head, neck, or arms showed a significantly greater muscle tension in these areas. This conclusion is consistent with the earlier findings of Malmo and Shagass (1949b) that psychiatric patients with cardiac complaints upon exposure to stress tend to manifest increased physiological responsiveness in the cardiovascular systems, while those with muscular symptoms respond in the muscular system.

Wolff (1948) reports that some anxious patients who were complaining of headache had a high level of muscle activity in the scalp and neck muscles. We have now confirmed this association in a controlled experiment in which the relation between headache and muscle tension in the frontalis was found to be a significant one. Malmo and Shagass (1949b) had recorded (during stress) more overactivity in the neck muscles of patients with head sensations than in those without. Our procedure, however, avoided the effects produced by movements, such as withdrawing the head from the painful stimulus, so that only muscle tension was scored.

Over-activity in a muscle and the subjective complaint of pain or discomfort in it are closely related. Wolff (1948) and Holmes and Wolff (1952) adduced experimental evidence that the sustained contraction of a muscle, such as occurs in emotionally disturbing situations, if sufficiently prolonged, will give rise to pain in it. If this is the case, then it appears likely that the mechanism underlying some "nervous headaches" is muscular tension, the latter being a part of the physiological changes accompanying the anxiety. Our findings suggest that often other painful muscular symptoms, some of those classed as "fibrositis", for instance, may be similarly produced. Another explanation might be derived from Jacobson's (1938) observation that when attention is concentrated upon a bodily area the number of action potentials increases there ; but the responses he recorded were much less than those we were finding. A third alternative might be sought in the familiar tendency for painful areas to be reflexly immobilized by muscular spasm. This could account for the tension in the neck muscles in headache, for example ; but it seems improbable that head sensations such as tight bands and 
pressure, or feelings of stiffness and discomfort in the arms, would provoke a response of comparable magnitude.

All our patients had been previously judged as tense and anxious by an independent clinical opinion. It was found that the symptoms reported most frequently were of a kind which could be attributed to muscular over-activity. This makes it likely that the recognition of muscle tension is often the observation which prompts the clinician to describe his patients as " tense". It would make for greater clarity if it were agreed to limit the clinical use of the term to this meaning.

From our findings, as well as those of Wolff (1948), and of Malmo and Shagass (1949a and b), it seems probable that some of the bodily symptoms in anxiety may be attributed to muscular over-activity, the latter being part of the physiological changes accompanying anxiety. Since patients who report feelings of tension have an increased muscular innervation, it is suggested that the feelings of irritability and restlessness of which they often complain may, in fact, be consequences of the massive bombardment of the central nervous system by proprioceptive stimuli arising from the widespread contraction of the voluntary muscles.

\section{Summary}

In 30 anxious and tense patients an inventory was made out recording their symptoms, their feelings (anxiety, tension, etc.), and their bodily complaints ascribable to muscular over-activity (head sensations, backache, etc.). The incidence of these complaints was shown.
A direct measure of the muscle tension of these patients was obtained by electronically summing the action potentials in the frontalis, forearm extensors and, in some, the neck muscles, while they relaxed. Reliable scores were obtained.

The patients were divided into two groups: those whose symptom scores on the inventory were above and those who were below the median. The muscle tension scores of the former were significantly higher in both the arms and forehead. Those with the most clinical manifestation of anxiety and tension, therefore, were the more muscularly over-active.

The patients were divided into those with and those without head, neck, or arm symptoms ; the former showed significantly higher muscle tension in the relevant muscle. The onset of headache during recordings was accompanied by significant increases in the innervation of the frontalis muscle.

Bodily symptoms attributable to a generalized alteration in muscular innervation, such as tremor and startle, were accompanied by significant increases in muscle activity in well-separated areas.

A significant concordance between four distinct muscle groups suggested that the body musculature as a whole receives increased innervation in patients? who are anxious.

\section{REFERENCES}

Cameron, D. E. (1944). Amer. J. Psychiat., 101, 36.
Holmes, T. H., and Wolf, H. G. (1952). Psychosomat. Med., 14, 18 Jacobson, E. (1938). Progressive Relaxation, 2nd ed., University of Chicago Press.

Chicago Press.
Malmo, R. B., and Shagass, C. (1949a). Psychosomat. Med., 11, 9.?
Wolff, H. G. (1948). Ibid., 11, 25. Press, New York. 